\title{
A randomised controlled trial of transforaminal endoscopic discectomy vs microdiscectomy
}

\author{
J. N. Alaistair Gibson ${ }^{1} \cdot$ Ashok S. Subramanian $^{1} \cdot$ Chloe E. H. Scott $^{1}$
}

Received: 29 June 2016/Revised: 24 October 2016/Accepted: 13 November 2016/Published online: 24 November 2016

(C) The Author(s) 2016. This article is published with open access at Springerlink.com

\begin{abstract}
Purpose Transforaminal endoscopic discectomy (TED) minimises paraspinal muscle damage. The aim of this trial was to compare clinical outcomes of TED to Microdiscectomy (Micro).

Methods 143 patients, age 25-70 years and $<115 \mathrm{~kg}$, with single level lumbar prolapse and radiculopathy, were recruited and randomised. 70 received TED under conscious sedation and 70 Micro under general anaesthesia. Oswestry Disability Index (ODI), visual analogue scores (VAS) of back and leg pain, and Short Form Health Survey indices (SF-36) were measured preoperatively and at 3,12 and 24 months.

Results All outcome measures improved significantly in both groups $(p<0.001)$. Affected side leg pain was lower in the TED group at 2 years $(1.9 \pm 2.6$ vs $3.5 \pm 3.1$, $p=0.002)$. Hospital stay was shorter following TED $(0.7 \pm 0.7$ vs $1.4 \pm 1.3$ days, $p<0.001)$. Two Micro patients and five TED patients required revision giving a relative risk of revision for TED of $2.62(95 \%$ CI 0.49-14.0).

Conclusions Functional improvements were maintained at 2 years in both groups with less ongoing sciatica after TED. A greater revision rate after TED was offset by a more rapid recovery.
\end{abstract}

Chloe E. H. Scott

chloe.scott@nhslothian.scot.nhs.uk

1 Department of Orthopaedics, Royal Infirmary of Edinburgh, 51 Little France Crescent, Old Dalkeith Road, Edinburgh EH16 4SA, UK
Keywords Lumbar discectomy · Microdiscectomy · Transforaminal endoscopic surgery $\cdot$ Randomised controlled trial

\section{Introduction}

Open spinal surgery comes at a cost of approach related morbidity. The importance of reducing muscle damage, particularly to the multifidus muscle that maintains segmental stability, has become well-recognised [1]. The concept that less aggressive decompression may yield better results has led to the development of minimally invasive techniques with microdiscectomy becoming commonplace in most centres.

In 1990, Kambin highlighted the potential access to the lumbar disc via the 'safe-working' zone or 'Kambin triangle' [2]. This precipitated interest in the transforaminal approach to the disc from within the canal [3-5], as an alternative to minimally invasive central nucleotomies (blind percutaneous endoscopic, automated percutaneous and laser discectomy) that lacked evidence of efficacy [6]. The ability to safely resect disc tissue by this method from inside the disc out [7], or outside in [8,9], has been recognised. Whether the theoretical advantages of transforaminal endoscopic (TED) surgery for symptomatic lumbar disc herniation are borne out by patient outcomes remains unclear. A systematic review has highlighted a paucity of evidence for the TED technique [9], in comparison to data now available in respect of microendoscopic approaches $[10,11]$. In view of the increasing use of transforaminal approaches to the spine, there is clearly a need for high-quality randomised controlled trials (RCTs) to determine whether TED is as effective as traditional microdiscectomy. 


\section{Patients and methods}

The aim of this prospective randomised controlled trial was to determine whether TED leads to equivalent, better or worse outcomes than the current 'gold standard' of microdiscectomy. A power sensitivity analysis suggested 140 patients were needed to detect a $10 \%$ difference in Oswestry Disability Index (ODI) improvement at 5\% significance, with $80 \%$ power and $10 \%$ loss to follow-up. Ethical approval was obtained and the study protocol published (http://www.controlled-trials.com/ISRCTN1155 6571)

The inclusion criteria were: age $25-70$, a single level prolapse with exiting and/or traversing nerve root compression and failure of conservative management ( $>6$ weeks of physiotherapy). Exclusion criteria were: upper lumbar disc disease (L2/3 or above), previous disc prolapse, massive sequestered disc prolapse, weight $>115 \mathrm{~kg}$, and malignancy.

\section{Randomisation}

All patients were randomised one week before surgery to receive either TED or Micro, by an off-site secretary using a random number generating computer program (block randomisation with odd numbers to TED and evens to Micro) [12]. This individual had no other involvement with the trial.

\section{Surgical procedures}

All TED were performed using a standardised transforaminal approach and 'outside-in' surgical technique using the TESSYS ${ }^{\mathrm{TM}}$ system (joimax GmbH, Germany) as previously described by Gibson et al. [9]. All surgery was performed or supervised by a senior spine surgeon with 1-year prior experience of TED and 25 years of experience with Micro. Patients were treated in the lateral position with the operating table 'broken' at the level of the affected disc. Conscious 'analgo-sedation' was administered as described by Godschalx [13]. Cannulae and endoscope placements were monitored using orthogonal bi-planar imaging (AP and lateral) with an image intensifier. No intra-operative discography was performed to outline the disc (to prevent possible internal disc fragmentation). After identification of the exiting root, pedicle and disc margin, all prolapsed material was excised using endoscopic rongeurs and a powered resector $\left(\right.$ Shrill ${ }^{\circledR}$, joimax $\mathrm{GmbH}$ ) ensuring that both the exiting and traversing roots lay free. Haemostasis was secured using a radiofrequency probe (Vaporflex ${ }^{\circledR}$ joimax GmbH/Surgimax, UK) with $\sim 0.02 \mathrm{~mm}$ penetration depth. Direct entry into the disc was avoided unless a central herniation was present. Proximal or distal disc material was accessed by angled graspers and cannula manipulation.

Microdiscectomy was performed using a standardised technique under general anaesthesia (GA). The ligamentum flavum was divided and the traversing nerve root identified and retracted under magnification (Zeiss, UK). Only prolapsed material was excised unless a fragment was herniating through the outer annulus in which case the disc was irrigated after prolapse extraction to ensure no sequestered fragments remained. Loose fragments underlying the posterior longitudinal ligament or extending into the exit foramen were cleared. A small $(<0.75 \mathrm{~cm})$ piece of absorbable haemostatic gelatin sponge (Spongostan $^{\mathrm{TM}}$, Ferrosan, Dk) was laid against the dura. No fat graft was inserted.

Immediate postoperative rehabilitation was identical for both treatment arms with a minimum of $2 \mathrm{~h}$ of bed rest before mobilisation. Patients were discharged home when comfortable and at two weeks postoperatively were allowed to drive, swim and return to work. Physiotherapy was offered if stiffness was present.

\section{Outcome assessments}

Patient reported outcome measures (PROMS) were collected prior to surgery and at 3,12 and 24 months, postoperatively. The Oswestry Disability Index (ODI, version 2a) [14] was applied and back and leg pain scored on horizontal visual analogue scales (VAS) [15]. General health was assessed using the Short Form SF-36 [16]. Patient satisfaction was assessed using Odom criteria [17]. SF-36 scores were converted into SF-6D scores [18] (a validated measure of health-related quality of life that can be used as an alternative to the EQ-5D) to calculate quality adjusted life years (QALYs) [19]. A change from baseline approach was implemented using preoperative and 2 year SF-6D scores. Life expectancy was assumed as 77.0 years for men and 81.4 years for women based on regional life expectancy (NHS Lothian region, Life Expectancy for Areas of Scotland 2008-2010). Time spent in the new health state was calculated as life expectancy minus age at surgery and was multiplied by the individual improvement in SF-6D score to calculate QALYs gained. This was discounted at a rate of $3.5 \%$ per year of life expectancy to reflect diminishing gain with age.

Work status and length of postoperative sickness absence were recorded at follow-up. Further magnetic resonance (MR) scans, reoperations and/or additional hospital admissions directly related to the same pathology were recorded. 


\section{Statistical analysis}

All analyses reported are as treated. This was identical to an intention-to-treat analysis, with the exception of one patient that crossed over from TED to Micro due to video equipment failure identified during anaesthetic induction. Data were analysed using SPSS Version 19.0 (SPSS Inc., Chicago, IL, USA). Continuous variables were plotted as histograms to assess normality. Parametric (unpaired $T$ tests) and non-parametric (Mann-Whitney $U$ ) tests were used to assess continuous variables for significant differences between TED and Micro. Nominal categorical variables were assessed using a Chi-square or Fisher's exact test. Relative risks were calculated for binary outcomes (repeat MR scan and revision). Repeated measures ANOVA was used to examine changes in parametric variables over the 2-year study period. A $p$ value of $<0.05$ was considered to be statistically significant. Post hoc analysis of PROMs changes over time was performed using paired $t$ tests. The significance level for this was set at $p<0.0125$ incorporating a Bonferroni correction to correct for multiple testing.

\section{Results}

Of 160 patients with a single-level disc prolapse assessed for eligibility to this trial, 143 met the inclusion criteria, who were recruited and randomised to the two treatment arms (Fig. 1). Three patients randomised to TED did not undergo any surgery and are not included in the analysis: one opted for nerve root injection and two underwent unrelated emergency surgery for other conditions and did not return for review. An additional patient randomised to TED underwent Micro due to equipment failure on the day of surgery. This patient has been included 'as treated' in the Micro group, giving 70 patients in each arm.

Baseline patient characteristics are shown in Table 1. Length of anaesthesia induction and operative time were equivalent (Table 2). A single radiographic image was used for level determination in Micro, thus radiation time and dosage was less than in TED. The TED group had a significantly shorter length of hospital stay (0.7 days \pm 0.7 , range $0-2$ vs 1.4 days \pm 1.3 , range $0-9$, $p<0.001)$.

\section{PROMs}

All PROMs improved significantly over the first 3 months following surgery in both groups $(p<0.001$, ANOVA Table 3; Figs. 2, 3). After Micro, ODI improved significantly to 1 year $(p=0.03)$ and VAS on the side of primary sciatica from 1 to 2 years $(p=0.005)$. After TED, ODI improved significantly to 1 year $(p=0.04)$ and PCS from 1 to 2 years $p=0.037)$. The VAS 'affected' leg pain score at 2 years was significantly less following TED $(1.9 \pm 2.6)$ than Micro (3.5 $\pm 3.1, p=0.002)$ (Fig. 2c). Patients were generally more satisfied after TED $(p=0.03$, Fig. $2 \mathrm{~d})$.

\section{Complications and revisions}

There were no major intra-operative or perioperative complications in either group. Two TED patients had significant headaches immediately postoperatively, possibly due to dural tears and CSF leakage. Both settled with bed rest for $12 \mathrm{~h}$. Four TED patients experienced mild dysaesthesia which settled within 2-4 weeks. One Micro patient had a persistent foot drop.

The number of additional MR scans and same level revision procedures performed within 2 years of the index surgery was higher in the TED group. Repeat MR was required in 14 TED patients compared to 6 Micro $(p=0.13$, Chi-squared test) giving a relative risk (RR) of repeat MR scan of 2.67 (95\% CI 0.96-7.41). Additional scans were performed at a mean of $41 \pm 18$ weeks (range 10-78) following TED and $51 \pm 8$ weeks (36-59) following Micro $(p=0.104)$. Revision surgery was required in 5 TED patients compared to 2 Micro $(p=0.44$, Fisher's exact test) giving an RR of 2.62 (0.49-14.0). TED patients underwent revision at 12, 26, 33, 56 and 60 weeks. Four had insidious recurrence of symptoms and one suffered an acute same level herniation after violent sneezing. The two Micro patients were revised at 51 and 60 weeks without any known new 'disc insult'.

The TED group utilised fewer physiotherapy sessions (mean $2.9 \pm 4.2$ vs $4.2 \pm 5.9, p=0.21$ ) and alternative therapy sessions (mean $0.3 \pm 1.4$ vs $0.5 \pm 1.8$, $p=0.193)$. This was not statistically significant.

\section{Quality of life}

The SF-6D health-related quality of life measure improved significantly to 2 years in both groups (Table 4). There was no significant difference in SF-6D improvement between groups or in QALYs gained, absolute or discounted (Table 4). Preoperatively, 116/140 patients (58 TED and 58 Micro) were in employment (Table 1), 12 of whom (7 TED and 5 Micro) worked part time. Forty-two of those in work required time off preoperatively due to their disc disease (24 TED and 16 Micro, $p=0.447$, Chi square). Postoperatively, patients returned to work at a median of 2 months in both groups $(p=0.89$, Mann-Whitney $U$ ). There was no significant difference in postoperative work status between groups ( $p=0.79$, Chi square, Fig. 4). Eight patients were unable to return to work (4 TED, 4 Micro). 


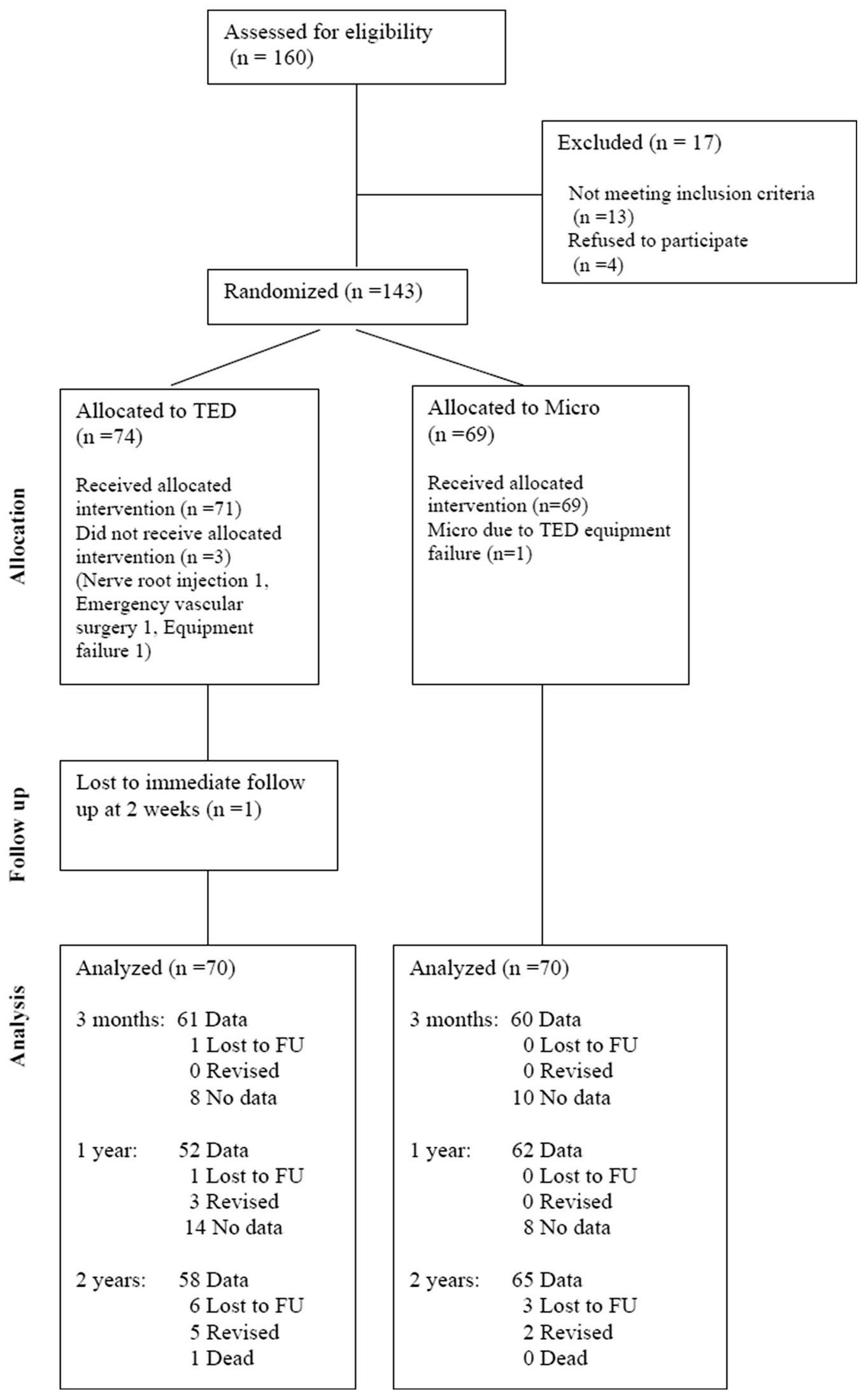

Fig. 1 Consort diagram of patient recruitment and retention 
Table 1 Baseline characteristics of the two groups

\begin{tabular}{|c|c|c|c|}
\hline & TED $(n=70)$ & $\operatorname{Micro}(n=70)$ & Comparison ( $p$ value) \\
\hline \multicolumn{4}{|l|}{ Demographics } \\
\hline Age in years (SD) & $42(9)$ & $39(9)$ & \multirow[t]{2}{*}{$0.76^{*}$} \\
\hline Age range & $26-69$ & $25-69$ & \\
\hline Female $(\%)$ & $40(57)$ & $30(43)$ & $0.09^{\mathrm{a}}$ \\
\hline Weight in kilograms (SD) & $76(17)$ & $81(17)$ & $0.95 *$ \\
\hline Weight range & $45-108$ & $45-115$ & \\
\hline Smoker (\%) & $30(43)$ & $20(29)$ & $0.11^{\mathrm{a}}$ \\
\hline Median symptom duration in months (range) & $18(4-120)$ & $15(3-120)$ & $0.54 * *$ \\
\hline \multicolumn{4}{|l|}{ Employment status } \\
\hline Employed (\%) & $58(83)$ & $58(83)$ & \multirow[t]{4}{*}{$0.32^{\mathrm{a}}$} \\
\hline Unemployed (\%) & $5(7)$ & $4(6$ & \\
\hline Retired (\%) & $4(6)$ & $1(1)$ & \\
\hline Unknown $(\%)$ & $3(4)$ & $7(10)$ & \\
\hline \multicolumn{4}{|l|}{ PROMs } \\
\hline ODI (SD) & $44(17)$ & $42(15)$ & $0.58 *$ \\
\hline VAS Back (SD) & $5.7(2.7)$ & $4.6(2.7)$ & $0.58 *$ \\
\hline VAS Affected Leg (SD) & $6.2(2.8)$ & $5.8(2.6)$ & $0.57 *$ \\
\hline VAS Non-affected Leg (SD) & $1.0(1.8)$ & $0.7(1.3)$ & $0.29 * *$ \\
\hline SF-36 PCS (SD) & $34.1(6.8)$ & $35.7(7.1)$ & $0.20 *$ \\
\hline SF-36 MCS (SD) & $38.1(13.1)$ & $37.9(12.4)$ & $0.91 *$ \\
\hline \multicolumn{4}{|l|}{ Surgical level } \\
\hline $\mathrm{L} 3 / 4(\%)$ & $0(0)$ & $2(3)$ & \multirow[t]{3}{*}{$0.05^{\mathrm{a}}$} \\
\hline $\mathrm{L} 4 / 5(\%)$ & $32(46)$ & $21(30)$ & \\
\hline L5/S1 (\%) & $38(54)$ & $47(67)$ & \\
\hline \multicolumn{4}{|l|}{ Disc position } \\
\hline Central & $19(27)$ & $17(24)$ & \multirow[t]{4}{*}{$0.88^{\mathrm{a}}$} \\
\hline Lateral & $38(54)$ & $39(56)$ & \\
\hline Foraminal & $10(14)$ & $12(17)$ & \\
\hline Extraforaminal & $3(4)$ & $2(3)$ & \\
\hline
\end{tabular}

Data are mean (standard deviation), median (range) or number (\%) as stated

* Unpaired $T$ test

** Mann-Whitney $U$

a Chi-squared

\section{Discussion}

Patient-reported outcomes following TED were not inferior to those following Micro and some were better. This supports a previous study comparing outcomes from a cohort study of TED and Micro data from the Swedish Spine Registry [20]. Pain in the affected leg was significantly better in the TED group at 2 years. This is in contrast to the findings of the 2014 Cochrane Review of all forms of minimally invasive discectomy (11 studies) that indicated that patients had less ongoing leg pain following open discectomy [21]. However, sample sizes were small and many of the studies were of questionable quality. We found no difference in back pain between treatments.
Improvements in ODI at 12 months for both TED and Micro were similar to those reported in the SPORT trial following Micro [22]. Patient-reported outcomes for TED were similar to those reported by Ahn et al. [23] in their recent retrospective analysis of outcomes following endoscopic discectomy (Yeung Endoscopic Spine System technique) in young soldiers.

In this trial, only patients with non-sequestered herniations are included. Distally migrated discs are amenable to transforaminal surgery [24] but it is technically difficult. Inclusion of these patients was thought at the trial outset to potentially introduce bias. A lower age limit of 25 was selected to exclude 'juvenile' type prolapses which have a different natural history. 
Table 2 Surgical outcome data

\begin{tabular}{llll}
\hline & TED $(n=70)$ & Micro $(n=70)$ & Comparison ( $p$ value $)$ \\
\hline Hospital stay in nights (SD) & $0.7(0.7)$ & $1.4(1.3)$ & $<0.001^{* *}$ \\
Hospital stay range & $0-2$ & $0-9$ & \\
Anaesthesia and set-up in minutes (SD) & $28(11)$ & $29(12)$ & $0.81^{*}$ \\
Incision to closure in minutes (SD) & $61(16)$ & $65(36)$ & $0.94^{*}$ \\
Radiation dose in cGy cm (SD) & $574(287)$ & $40(31)$ & $<0.001^{* *}$ \\
Radiation time in minutes (SD) & $0.98(0.45)$ & $0.05(0.09)$ & $<0.001^{* *}$ \\
Number revised by 2 years (\%) & $5(7)$ & $2(3)$ & $0.44^{* * *}$ \\
Time to revision in weeks (SD) & $46 \pm 16$ & $60 \pm 1$ & $0.02^{* *}$ \\
\hline
\end{tabular}

Means (standard deviation), number (\%)

* Unpaired $T$ test

** MannWhitney $U$ test

*** Fisher's exact test

Table 3 Postoperative patientreported outcome measures

\begin{tabular}{|c|c|c|c|}
\hline & TED $(n=70)$ & $\operatorname{Micro}(n=70)$ & Comparison ( $p$ value) \\
\hline \multicolumn{4}{|l|}{ ODI } \\
\hline 3 months (SD) & $27(18)$ & 27 (18) & $0.84 * *$ \\
\hline 1 year $(\mathrm{SD})$ & $22(20)$ & $22(19)$ & $0.95 * *$ \\
\hline 2 years $(\mathrm{SD})$ & $18(17)$ & $22(20)$ & $0.15^{* *}$ \\
\hline \multicolumn{4}{|l|}{ VAS back } \\
\hline 3 months (SD) & $3.0(2.7)$ & $3.1(2.9)$ & $0.66 * *$ \\
\hline 1 year $(\mathrm{SD})$ & $3.1(3.1)$ & $3.1(2.7)$ & $0.67 * *$ \\
\hline 2 years $(\mathrm{SD})$ & $2.5(2.5)$ & $3.0(2.8)$ & $0.45^{* *}$ \\
\hline \multicolumn{4}{|l|}{ VAS affected leg } \\
\hline 3 months (SD) & $2.8(2.9)$ & $3.2(3.2)$ & $0.45^{* *}$ \\
\hline 1 year $(\mathrm{SD})$ & $2.6(3.1)$ & $2.7(2.8)$ & $0.54 * *$ \\
\hline 2 years $(\mathrm{SD})$ & $1.9(2.6)$ & $3.5(3.1)$ & $0.001 * *$ \\
\hline \multicolumn{4}{|c|}{ VAS non-affected leg } \\
\hline 3 months (SD) & $0.3(0.9)$ & $0.5(1.4)$ & $0.04 * *$ \\
\hline 1 year $(\mathrm{SD})$ & $0.5(1.7)$ & $0.7(1.8)$ & $0.11 * *$ \\
\hline 2 years $(\mathrm{SD})$ & $0.6(1.5)$ & $0.8(1.8)$ & $0.43^{* *}$ \\
\hline \multicolumn{4}{|l|}{ SF-36 PCS } \\
\hline 3 months (SD) & $42.4(9.6)$ & $43.1(8.6)$ & $0.65^{*}$ \\
\hline 1 year $(\mathrm{SD})$ & $45.0(10.9)$ & $45.1(10.8)$ & $0.97 * *$ \\
\hline 2 years $(\mathrm{SD})$ & $47.7(10.6)$ & $47.4(10.6)$ & $0.69 * *$ \\
\hline \multicolumn{4}{|l|}{ SF-36 MCS } \\
\hline 3 months (SD) & $44.6(14.2)$ & $43.7(14.4)$ & $0.68 * *$ \\
\hline 1 year $(\mathrm{SD})$ & $47.9(14.8)$ & $44.8(13.9)$ & $0.13 * *$ \\
\hline 2 years $(\mathrm{SD})$ & $49.4(14.1)$ & $45.2(14.8)$ & $0.06 * *$ \\
\hline
\end{tabular}

Mean (standard deviation)

$O D I$ Oswestry Disability Index, VAS Visual Analogue Scale for pain, $P C S$ physical component score, $M C S$ mental component score

* Unpaired $T$ test

** Mann-Whitney $U$ test
Symptom duration prior to surgery displayed a broad range. Sub-analysis of the SPORT trial [22] has indicated that patients with greater than 6 months of symptoms risk inferior results. Most of our patients reported a history of some symptoms at a mean of 2 years before surgery and we were not able to discriminate 'acute' symptoms with 


\section{A Oswestry Disability Index}

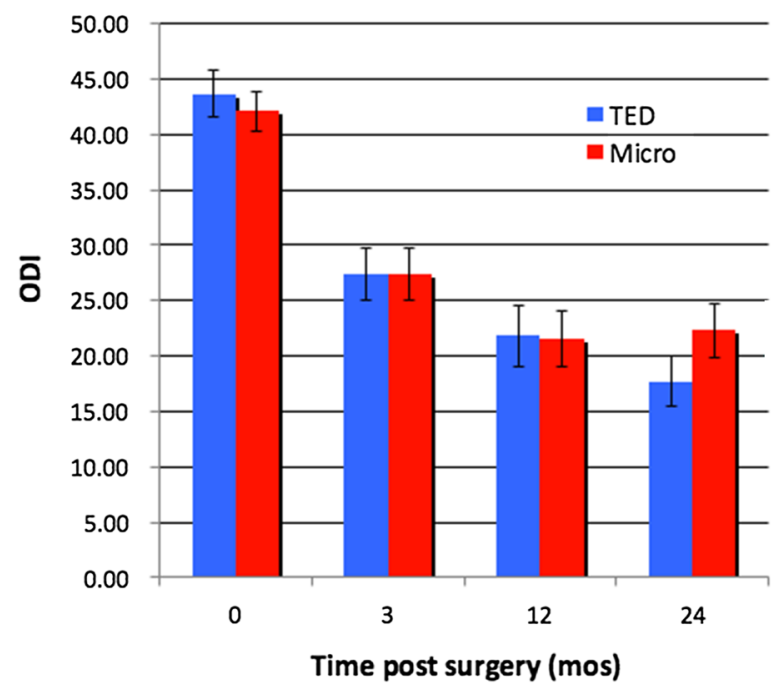

C Most Affected Leg - Pain

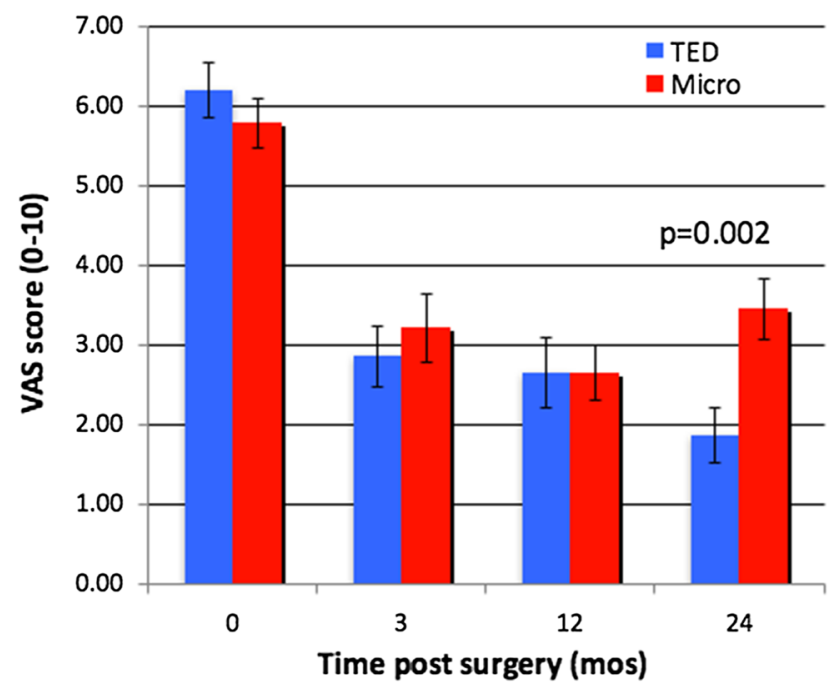

\section{B Back Pain}

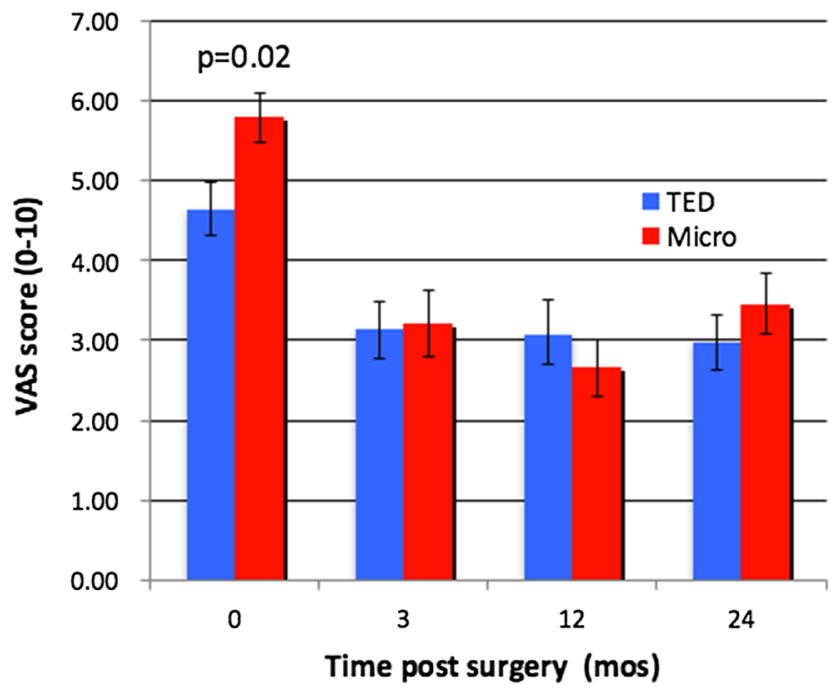

D Odom's criteria (1-4)

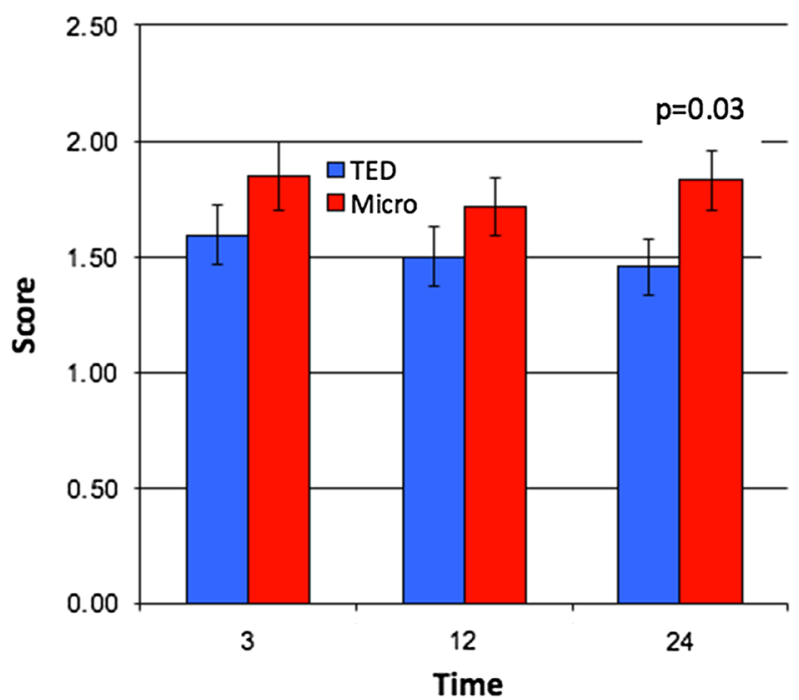

Fig. 2 Patient-reported outcome measures a Oswestry Disability Index (ODI), b Visual Analogue Scale (VAS) for back pain, c VAS for leg pain, $\mathbf{d}$ Odom's criteria

accuracy. However, symptom duration was similar in both groups. Once in contact with the surgical service, the preoperative rehabilitation regime was standardised for all patients. We cannot comment on the effect or nature of any other prior non-operative management. Following surgery, patients were referred for physiotherapy if they complained of stiffness. Alternative therapies were not prescribed, but if received, were sourced independently by the patient and may represent a possible source of bias between groups.

We recognise that anaesthetic methods differed between the treatment arms in this trial with conscious sedation rather than GA chosen for TED as a 'patient reporting' safeguard against nerve root injury. Although the difference in anaesthesia did not materially alter the length of the surgical procedure (the longer GA induction for the Micro group was balanced by a longer theatre 'set-up' time for TED) it should be accepted that a shorter 'wake-up' after surgery would have contributed to the reduced hospital stay noted in the TED group. This difference may not have been as pronounced if GA had been used in both groups. Radiation doses for both procedures were well within safe ranges $(<3 \%$ of accepted Dose Area Product threshold of $500 \mathrm{~Gy} \mathrm{~cm}^{2}$ ) [25].

The site of disc prolapse was similarly distributed in both treatment arms. The transforaminal approach is particularly suited to excision of 'far-out' prolapse and 
A SF-36 Physical component score

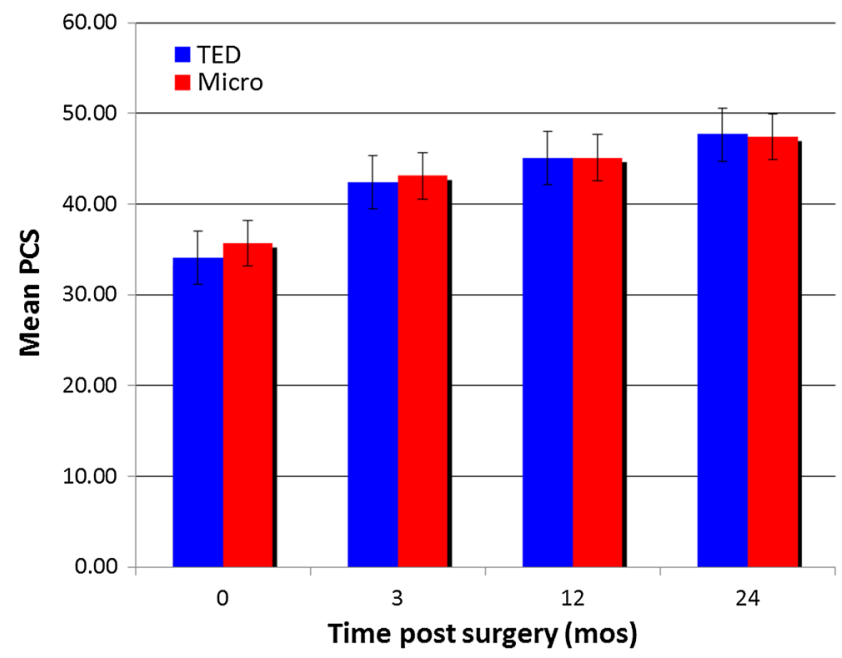

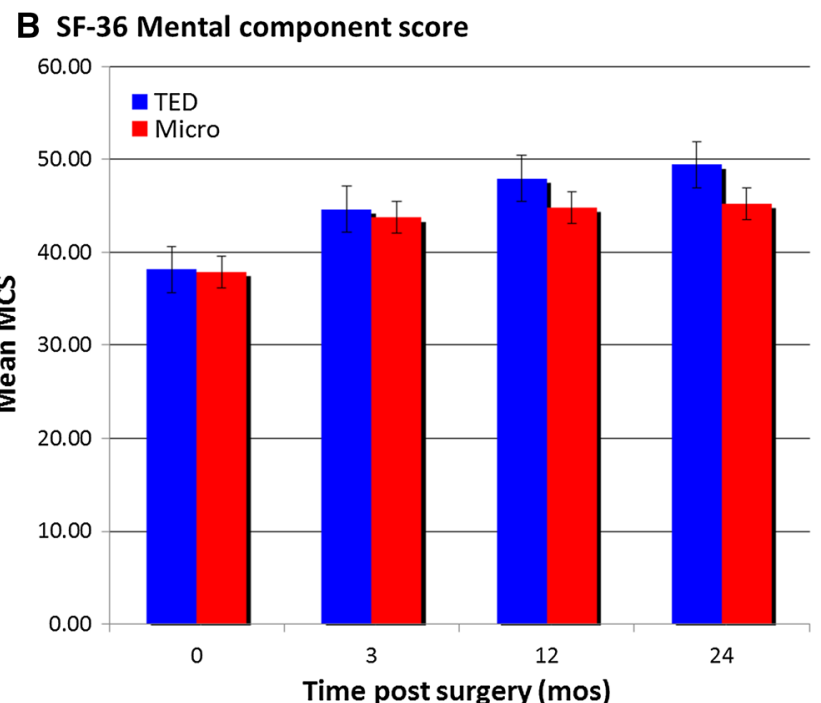

Fig. 3 SF-36 scores a physical component score (PCS) and b mental component score (MCS)

Table 4 Health-related quality of life

\begin{tabular}{llll}
\hline & TED $(n=70)$ & Micro $(n=70)$ & Comparison $(p$ value $)$ \\
\hline SF-6D & & & \\
$\quad$ Preoperative (SD) & $0.534(0.09)$ & $0.531(0.09)$ & $0.88^{*}$ \\
1 year (SD) & $0.666(0.16)$ & $0.670(0.15)$ & $0.97^{* *}$ \\
2 years (SD) & $0.693(0.18)$ & $0.689(0.16)$ & $0.39^{* *}$ \\
QALYs gained at 2 years: absolute (SD) & $5.944(6.6)$ & $6.041(7.1)$ & $0.95^{*}$ \\
QALYs gained at 2 years: discounted (SD) & $1.640(1.7)$ & $1.412(1.5)$ & \\
\hline
\end{tabular}

Mean (standard deviation)

QALYs quality-adjusted life years

* Unpaired $T$ test

** Mann-Whitney $U$ test

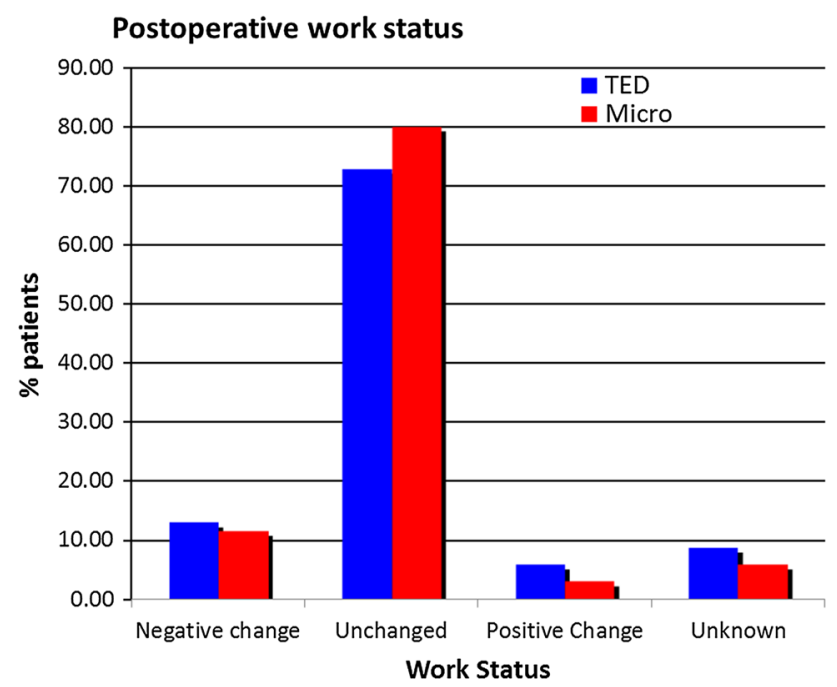

Fig. 4 Return to work status. Negative changes include reduced working hours or an inability to work due to disc disease. Positive changes include an increase in working hours or re-employment widening of the foramen for the exiting nerve root [26]. In contrast, Micro provides easier access to the lateral recess of the canal, although possibly with greater epidural scarring [27]. Access to the L5/S1 disc during TED may be difficult if the patient's pelvic crest is high. In this series, L5/S1 disc access was facilitated by careful patient positioning using a 'broken' operating table and no patient required intra-operative conversion to Micro.

Transforaminal endoscopic surgery is associated with a significant learning curve [28]. All five revisions in the TED arm of the trial were within the first two-thirds of the study. As surgical experience with TED increases and technology advances, the incidence of revision would be expected to decline.

The combined rate of revision surgery at $5 \%$ was within that expected from most reported studies of discectomy. Of those revised, five opted for Micro as a second operation. One patient chose to have repeat TED achieving a good outcome. The reported absence of scarring at revision of 
TED [29] has important implications for longer-term outcomes in terms of the ease of revision surgery. The reduction in tissue disruption provided by the TED technique may also have important effects on outcome via a reduction in cytokine release lessening the overall inflammatory response to surgery [30]. In this trial, patients who underwent revision were included in our outcome data only up to the point of revision. This point was considered to represent their worst outcome scores as all patients improved following revision surgery. Had outcome scores subsequent to revision procedures been included this may have falsely improved 1 and 2 year results. On this basis, we found no significant difference in quality of life improvement between the treatment arms at 2 years.

Weaknesses of this study include the non-blinded nature of the trial. Both surgeon and patient were aware of their treatment and the senior surgeon acknowledges a specific interest in endoscopy which may introduce bias. However, all outcomes were collected independently and are patient reported. The data were scrutinised by all authors. Different anaesthetic techniques were used which may favour shorter length of stay in the TED group. This was pragmatic as it was considered safer to perform TED under conscious sedation. Though length of stay was significantly shorter in the TED group, this was a secondary outcome measure and the study was not powered to detect differences therein. No record was made of any litigation pertaining to any presenting injury. Finally, data were analysed "as treated" not as "intention-to-treat". This was considered acceptable as only one case crossed over between treatment arms and this was due to equipment failure not clinical choice. Thirteen patients $(9.3 \%)$ were lost to follow-up by 2 years. This was within the $10 \%$ allowed by our power calculation and was significantly less than the $20 \%$ required by a level 1 trial.

\section{Conclusions}

Transforaminal endoscopic discectomy and microdiscectomy give comparable outcomes. A reduced length of hospital stay and less leg pain at 2 years following TED are offset by a greater requirement for repeat MR scans and revision surgery. Although a learning curve applies for this technique, the lack of requirement for general anaesthesia and a mean length of stay under 1 day makes TED an ideal technique for use in day-case units.

\section{Compliance with ethical standards}

Conflict of interest We have no potential conflict of interest.

Open Access This article is distributed under the terms of the Creative Commons Attribution 4.0 International License (http:// creativecommons.org/licenses/by/4.0/), which permits unrestricted use, distribution, and reproduction in any medium, provided you give appropriate credit to the original author(s) and the source, provide a link to the Creative Commons license, and indicate if changes were made.

\section{References}

1. Ward SR, Kim CW, Eng CM et al (2009) Architectural analysis and intraoperative measurements demonstrate the unique design of the multifidus muscle for lumbar spine stability. J Bone Jt Surg Am 91(1):176-185

2. Kambin P (1991) Arthroscopic Microdiscectomy Minimal Intervention. In: Kambin $P$ (ed) Spinal Surgery. Text Urban and Schwarzenberg Baltimore, MD, pp 67-100

3. Hoogland T, Scheckenbach C (1998) Die endoskopische transforaminale diskektomie bei lumbalen bandscheibenforfallen. Orthop Prax 34:352-355

4. Hoogland T (2003) Transforaminal endoscopic discectomy with foraminoplasty for lumbar disc herniation. Surg Tech Orthop C40:55-120

5. Kim M, Lee S, Jung E et al (2007) Targeted percutaneous transforaminal endoscopic diskectomy in 295 patients: comparison with results of microscopic diskectomy. Surg Neurol 68(6):623-631

6. Gibson JNA, Waddell G (2007) Surgical interventions for lumbar disc prolapse. Cochrane Database Syst Rev 18(2):CD001350. doi: $10.1002 / 14651858$

7. Yeung AT, Tsou PM (2002) Posterolateral endoscopic excision for lumbar disc herniation: surgical technique, outcome, and complications in 307 consecutive cases. Spine (Phila Pa 1976) 27(7):722-731

8. Hoogland T, Schubert M, Miklitz B, Ramirez A (2006) Transforaminal posterolateral endoscopic discectomy with or without the combination of a low-dose chymopapain: a prospective randomized study in 280 consecutive cases. Spine 31(24):E890-E897

9. Gibson JNA, Cowie J, Iprenburg M (2012) Transforaminal endoscopic spinal surgery: the future 'gold standard' for discectomy? A Review. Surgeon 10(5):290-296

10. Smith N, Masters J, Jensen C, Khan A, Sprowson A (2013) Systematic review of microendoscopic discectomy for lumbar disc herniation. Eur Spine J 22(11):2458-2465

11. He J, Xiao S, Wu Z, Yuan Z (2016) Microendoscopic discectomy vs open discectomy for lumbar disc herniation: a metaanalysis. Eur Spine J 25(5):1373-1381

12. Haar M (1998) True random number generator. http://www.ran dom.org. Accessed 25.08.16

13. Godschalx A (2008) Caveats of monitored anesthesia for percutaneous transforaminal endoscopic spinal surgery. In: Lewandrowski $\mathrm{K}$ et al (eds) Minimally invasive spinal fusion techniques. Summit Communications, LLC, NY, pp 37-47

14. Fairbank JC, Pynsent PB (2000) The Oswestry Disability Index. Spine 25(22):2940-2952

15. Price D, McGrath P, Rafii A, Buckingham B (1983) The validation of visual analogue scales as ratio scale measurements for clinical and experimental pain. Pain 17(1):45-56

16. Jenkinson C, Coulter A, Wright L (1993) Short form 36 (SF36) health survey questionnaire: normative data for adults of working age. BMJ 306:1437-1444

17. Odom GL, Finney W, Woodhall B (1958) Cervical disk lesions. J Am Med Assoc 166(1):23-28

18. Brazier J, Roberts J, Deverill M (2002) The estimation of a preference-based measure of health from the SF-36. J Health Econ 21(2):271-292 
19. Whitehead SJ, Ali S (2010) Health outcomes in economic evaluation: the QALY and utilities. Br Med Bull 96:5-21

20. Iprenburg M, Godschalx A (2008) Transforaminal endoscopic surgery in lumbar disc herniation in an economic crisis- the TESSYS method. US Musculoskelet Rev 3(2):47-49

21. Rasouli MR, Rahimi-Movaghar V, Shokraneh F et al (2014) Minimally invasive discectomy versus microdiscectomy/open discectomy for symptomatic lumbar disc herniation. Cochrane Database Syst Rev. doi:10.1002/14651858.CD010328.pub2

22. Weinstein JN, Tosteson TD, Lurie JD et al (2008) Surgical vs nonoperative treatment for lumbar disc herniation. Four-year results for the Spine Patient Outcomes Research Trial (SPORT). Spine 33(25):2789-2800

23. Ahn SS, Kim SH, Kim DW et al (2016) Comparison of outcomes of percutaneous endoscopic lumbar discectomy and open lumbar microdiscectomy for young adults: a retrospective matched cohort study. World Neurosurg (United States) 86:250-258

24. Yeom KS, Choi YS (2011) Full endoscopic contralateral transforaminal discectomy for distally migrated lumbar disc herniation. J Orthop Sci 16(3):263-269
25. Stecker MS, Balter S, Towbin RB et al (2009) Guidelines for patient radiation dose management. J Vasc Interv Radiol $20(7$ Suppl):S263-S273

26. Schubert M, Hoogland $T$ (2005) Endoscopic transforaminal nucleotomy with foraminoplasty for lumbar disk herniation. Oper Orthop Traumatol 17(6):641-661

27. Fritsch EW, Heisel J, Rupp S (1996) The failed back surgery syndrome: reasons, intraoperative findings and long-term results: a report of 182 operative treatments. Spine 21(5):626-633

28. Hsu H-T, Chang SJ, Yang SS, Chai CL (2013) Learning curve of full-endoscopic lumbar discectomy. Eur Spine J 22(4):727-733

29. Hoogland T, van den Brekel-Diijkstra K, Schubert M, Miklitz B (2008) Endoscopic transforaminal discectomy for recurrent lumbar disc herniation. Spine 33(9):973-978

30. Elkan P, Sten-Linder M, Hedlund R, Willers U, Ponzer S, Gerdhem P (2016) Markers of inflammation and fibrinolysis in relation to outcome after surgery for lumbar disc herniation. A prospective study on 177 patients. Eur Spine J 25(1):186-191 